\title{
Should EFL Teachers Present Vocabulary in Semantically Related Sets?
}

\author{
Amparo LÁzaro Ibarrola \\ Public University of Navarre \\ María Ángeles Hidalgo Gordo \\ University of the Basque Country
}

Received: 17 May 2013 / Accepted: 27 May 2014

ISSN: $1697-7467$

\begin{abstract}
Teaching vocabulary in semantically related sets is common practice among EFL teachers. The present study tests the effectiveness of this method by comparing it to the alternative technique: presenting vocabulary in an unrelated way. In the study two intact classes of Spanish learners of English in high-school were presented with a set of unrelated and related words and were then asked to complete a post-test to measure the impact of both techniques on learning. The results indicate that, while both techniques successfully help the learners to acquire new words, presenting words in unrelated sets seems to be more effective. Keywords: vocabulary, EFL, semantically related sets, semantically unrelated sets.
\end{abstract}

\section{¿Deberían los profesores de inglés como lengua extranjera presentar el vocabulario agrupado en campos semánticos?}

RESUMEN: La enseñanza de vocabulario agrupado en campos semánticos es práctica habitual en el aula de inglés como lengua extranjera. En este estudio se compara esta técnica con su contraria, la presentación de vocabulario no relacionado, con dos grupos de alumnos de un instituto. Tras presentar las palabras con ambas técnicas los alumnos completaron un post-test. Los resultados muestran la efectividad de ambas técnicas pero con una ligera ventaja para la enseñanza de vocabulario no relacionado semánticamente.

Palabras clave: vocabulario, inglés como lengua extranjera, palabras de un mismo campo semántico, palabras de distinto campo semántico.

\section{InTRODUCTION}

On many occasions, foreign language teachers base their practices on popular beliefs about language learning or they simply take the validity of previous practices for granted and teach as they were taught. Thus, they perpetuate practices whose effects on learning have not been tested empirically, or have been tested but the results have not reached the hands of teachers, or have been tested in laboratory conditions and the results cannot be extrapolated to the real classroom. Bearing this in mind, the present paper aims to test one specific belief that is very widely spread and that has translated into common teaching practice: the belief that teaching vocabulary items that are semantically related at the same time enhances the acquisition of vocabulary. 
This belief is clearly reflected in language textbooks that usually present vocabulary in semantically related fields, probably not so much because this seems to reinforce learning but mainly because it fits the topic-centred approach to language teaching that textbooks usually follow in order to meet the communicative needs of the students. In fact, we are so used to this approach that it would be hard to think of a different way to design and organize textbook and classroom contents.

In order to empirically test the validity of presenting vocabulary in semantically related fields, the present study compares the effectiveness of this technique and the alternative option, that is, the presentation of new vocabulary in an unrelated fashion. In doing so, this study closely replicates a previous study carried out by Papathanasiou (2008), who explored both possibilities with Greek students of English as a foreign language (henceforth EFL). Thus, we will be able to compare our results and extend or qualify the validity of her findings.

Finally, following the principles and theories of action research, the whole experiment took place in the classroom and within the classroom limitations. Contrary to what happens with laboratory studies, this classroom focus allows us to measure the effectiveness of the techniques in real classroom conditions and to argue for or against their use in EFL classrooms.

\section{THEORETICAL FRAMEWORK}

Vocabulary is an essential part of the language. Although the acquisition of vocabulary occurs naturally in native speakers, L2 learners spend a great amount of time memorising lists of words as part of their L2 learning process. Even at advanced levels, L2 learners are aware of the deficit or limitations in their knowledge of the target language words, experiencing lexical gaps (Read 2000), that is, moments when they do not understand a word they read or hear, or cannot express a concept in the way they would in their mother tongue. It is not surprising, then, that vocabulary has attracted the attention of many researchers and teachers, and great amounts of time and efforts have been devoted to the study of different approaches to teach vocabulary in a more effective way (Bogaards and Laufer, 2004; Coady and Huckin, 1997; Read, 2000; Richards and Renandya, 2002). However, firm conclusions have not been reached on several issues (Erten and Tekin, 2008) and "the teaching of vocabulary has fallen in the same pit of controversy in which many other literacy practices have landed" (Allen, 1999: 5).

The present study focuses on one particularly controversial topic: What is more effective: to present new vocabulary in semantically related or unrelated sets? When advocating for one technique or the other, the only agreement that has been clearly reached is that there is a strong disagreement mostly between theoretical and experimental evidence.

On the one hand, as Papathanasiou (2008) points out, arguments supporting the validity of the presentation of related lexical items together are mainly based on theoretical evidence. Based on the idea that the mind uses semantic similarities when classifying words (Channell, 1981), it is also believed that the presentation of semantically related words together will allow learners to compare the words and, consequently, it will help them make meaning clearer. In fact, most of the arguments in favor of presenting words in semantically related sets are based on the fact that it reflects the natural organization of the mental lexicon (Aitchison, 1994, 1996; Grandy, 1992; Hashemi and Gowdasiaei, 2005; Haycraft, 1993; Seal, 1991; Stoller and Grabe, 1995; Wharton and Race, 1999). 
Willis and Willis (2007) highlight the importance of lexis on language teaching, and argue that designing and using topic-based tasks, and teaching lexis in meaningful sets, is indeed useful to develop learners' ability to use English for meaning and real communication. This belief is clearly reflected in the structure of EFL course books, which are usually divided into units presenting semantically related words, following the course book writers' own perception of the learners' communicative needs (Papathanasiou 2008). Obviously, teacher practices are very often shaped by course books but this structure also affects the students, who often express their preference for semantically related sets (Erten and Tekin, 2008).

In stark contrast to these theoretically substantiated opinions, most experimental evidence has found negative effects when presenting semantically related word sets. In some cases even suggesting that semantic clusters impede, rather than facilitate learning (Anderson, 2003; Erten and Tekin, 2008). Some studies from the 90s had already warned about the disadvantages of presenting words in semantic fields. Tinkham $(1993,1997)$ and Waring (1997) found that students needed more time to learn new lexical items when these were presented in related sets. Finkbeiner and Nicol (2003) evinced that learners translated terms at a slower rate when dealing with semantically related vocabulary sets. Also, Schneider, Healy, and Bourne (1998) found that the learning of words in related sets, although in the short-term seemed to be more helpful to learners, did not prove completely satisfactory for long-term retention.

More recently, Erten and Tekin (2008) carried out an experimental study with 60 students who were taught 80 words either in semantically related or in semantically unrelated sets. They found that learning words in semantically unrelated sets yielded significantly better results. What is more, they also found that test completion time was much longer for the semantically related vocabulary items, indicating a slower recall of vocabulary. They concluded that, due to cross-association (that is, mixing meanings and forms of the words in the same set), teaching vocabulary in semantically related sets hinders vocabulary learning and, consequently, this common practice should be reconsidered. In order to avoid crossassociation, Nation (2000) suggests that semantically related sets could be used only once the items have been learned in isolation and, in addition to this, when presenting semantically related words, teachers should not pay attention to the semantic relations between them.

On the other hand, Papathanasiou (2008), whose work we intend to partially replicate here, introduced a level and age variable. More specifically, this author compared the effectiveness of semantically related and semantically unrelated word sets with two groups of Greek EFL learners in a language school: a group of 31 children with an intermediate level and a group of 32 adult beginners. Papathanasiou (2008) presented 60 English words with their Greek equivalents in semantically related and unrelated sets alternatively to both groups for a period of three weeks. At the end of the third week, a test was administered to both classes and two weeks later, both classes were tested again. The results demonstrated that presenting new words in semantically unrelated sets facilitated vocabulary retention for the adult beginners, while a firm conclusion was not reached for the intermediate children.

In conclusion, while theoretical work advocates for the presentation of new vocabulary in related word sets, results from empirical studies have shown the disadvantages of this technique and advocate for the presentation of vocabulary in semantically unrelated sets (Folse, 2004). Following Papathanasiou (2008), unrelated word sets were especially effective in the case of adult beginners. 
Finally, it is well known that "students of foreign languages often rely on various strategies to memorize vocabulary words" (Saphiro and Waters, 2005: 129) and, in fact, it has been demonstrated that learners with strategic knowledge of language learning acquire a language more easily (Tseng, Dornyei and Schmitt, 2006). Accordingly, several authors have set off to investigate the effects of strategy training on the acquisition of vocabulary and have demonstrated that it improves vocabulary retention. For instance, Çalişkan and Sünbül (2011) studied the effect of direct teaching of learning strategies and, despite some limitations, their overall results show an advantage for learners receiving strategy training. Nemati (2009) also found that learners' awareness of strategies facilitates vocabulary acquisition, both in long-term and short-term retention. Given the pedagogical relevance of this finding, some authors have provided practical suggestions and useful tips for strategy training, which include direct teaching of strategies, awareness raising activities and development of an adequate self-regulatory capacity (Khalil, 2005; Tseng, Dornyei and Schmitt, 2006; Xhaferi and Xhaferi, 2008; Zhi-liang, 2010). Following some of these suggestions, in the present paper the words have been presented with their visual image, with their definition in English, with their Spanish translation and with a mini-context (sentences and fill-in-the-gaps exercises). Also, students were asked to interact with other students (constructing sentences with the new words). This means that the learners of the present study had to make use of the main types of vocabulary learning strategies (cognitive, metacognitive, memory and social). The same teaching strategies were included in both methods (related and unrelated set) in order to maintain their comparability.

\section{RESEARCH QUESTIONS AND HYPOTHESIS}

The present study compares two techniques for presenting vocabulary, in semantically related and in semantically unrelated word sets, with two groups of Spanish students of English in secondary school. In one group the students have a beginner level of proficiency and in the other group they have an intermediate level. Therefore, the following research question was formulated:

Are the two forms of presenting vocabulary (in semantically related and unrelated word sets) equally effective for the acquisition of new words in the two groups?

Based on the empirical studies referred to above, an advantage for the semantically unrelated set would be expected and, according to Papathanasiau (2008), this advantage might be greater in the beginner group.

\section{Method}

\subsection{Participants}

This study was carried out with two intact groups of students who are learning EFL in a private secondary school in Spain. One of the groups has 33 fifteen-year-olds and the other 24 eighteen-year-olds. According to internal school tests and following the Common 
European Framework of Reference for Languages (Council of Europe 2001), the level of English of the thirteen-year-olds was equated to an A1 level (beginner), while the eighteenyear-olds had reached level B1 (intermediate). Accordingly, from now on we will be referring to both groups as Beginner Group (BG) and Intermediate Group (IG).

\subsection{Procedure}

The whole experiment took a total of five school sessions (one per week). All the learners in the BG and in the IG experienced both techniques. Table 1 features the details about the chronological distribution of the sessions.

Table 1: Procedure.

\begin{tabular}{|c|c|c|c|c|}
\hline $\begin{array}{c}\text { Session 1 } \\
\text { Week 1 }\end{array}$ & $\begin{array}{c}\text { Session 2 } \\
\text { Week 2 }\end{array}$ & $\begin{array}{c}\text { Session 3 } \\
\text { Week 3 }\end{array}$ & $\begin{array}{c}\text { Session 4 } \\
\text { Week 4 }\end{array}$ & $\begin{array}{c}\text { Session 5 } \\
\text { Week 5 }\end{array}$ \\
\hline Pilot Test & $\begin{array}{c}\text { Presentation } \\
\text { of the unrelated } \\
\text { word set }\end{array}$ & $\begin{array}{c}\text { Post-test with the } \\
\text { semantically } \\
\text { unrelated words }\end{array}$ & $\begin{array}{c}\text { Presentation } \\
\text { of the related } \\
\text { word set }\end{array}$ & $\begin{array}{c}\text { Post-test with the } \\
\text { semantically rela- } \\
\text { ted words }\end{array}$ \\
\hline
\end{tabular}

As can be seen in Table 1, during the first week a pilot test was administered to elicit words that the students did not know. The objective was to ensure that all the words used in both treatments were new to all the learners. The implementation and testing of the semantically unrelated words took the second and third week and, finally, the implementation and testing of the semantically related words took the following two weeks. The sessions went as follows.

Pilot Test (Session 1): In the first session the learners were provided with a list of 60 English words and they were asked to tick those they already knew. Following the pilot test results, 10 words unknown to all the students were selected for the unrelated set and 10 for the semantically related set. The selected words were the following:

(i) Unrelated word set: beak; bush; tailor; sleeve; grab; currency; lawnmower; steamed; butler; coal.

(ii) Related word set (words related to the city): ditch; sewer; tramp; cul-de-sac;

launderette; outskirts; railings; passer-by; downtown; kerb.

Presentation of new vocabulary (Sessions 2 and 4): The ten words from the corresponding set were presented to the students (the unrelated words in session 2 and the related words in session 4). As in Papathanasiou's (2008) study, the words were presented in isolation in order to assess the subjects' ability to supply meaning when given a target word. The presentation stage consisted of a Power Point presentation in which the words were first presented in the auditory form and then the learners were asked to repeat the words and write them down. Finally, the learners were given the definitions of the words in English, 
their written form and their Spanish translation. When the presentation was over the learners had to do an exercise that consisted of matching every word with the corresponding English definition and Spanish translation. Finally, they did a consolidation activity consisting of a fill in the gap exercise (See Appendix A for the actual lesson plan followed by the researchers to present the words).

Post-tests (Sessions 3 and 5): The 10 words from each set together with their definitions were presented to the students in English and they were asked to match them with the corresponding definitions and Spanish translations, just as they had done in the presentation sessions (See Appendix B for the sample tests used to measure retention of the new vocabulary). The unrelated words were tested in session 3 , one week after these words had been presented to the students. The related words were tested in session 5, also one week after these words had been presented to the students.

Finally, it is important to explain that the procedure was exactly the same for both treatments; this implies the same teacher, materials, time, etc. Also, to ensure the ecological validity of the study, in both cases the activities were integrated as part of the regular classroom activities.

\section{Results AND DiscusSion}

Table 2 features the results regarding post-test scores for both groups in both treatments. The numerator corresponds to the total number of correct words in the post-test and the denominator to the total number of words put to the test (10 per person, per test).

Table 2: Group results: Rate of correct words in post-tests.

\begin{tabular}{|c|c|c|}
\hline & Unrelated Word set & Related Word set \\
\hline IG & $88,75 \%$ & $73,75 \%$ \\
18-year-olds & $(213 / 240)$ & $(177 / 240)$ \\
$(24$ learners $)$ & & $1,51 \%$ \\
\hline BG & $64,84 \%$ & $(170 / 330)$ \\
(33 learners) & $(214 / 330)$ & \\
\hline
\end{tabular}

As can be seen in Table 2, both groups have scored over 50 per cent in both tests. The IG has outperformed the BG with both treatments and both groups have obtained higher scores with the unrelated words, the advantage being greater in the IG. This suggests (i) that both techniques successfully help the learners to acquire new words; (ii) that, as expected, presenting words in unrelated sets seems to be more effective for vocabulary learning and, finally, (iii) that it seems that the higher the level of the target language the greater the capacity to acquire new vocabulary. 
A deeper analysis of the individual scores helps to qualify these initial group results. Table 3 features the results of the IG and Table 4 those of the BG. The tables show the number of correct words in the post-tests for every participant.

Table 3: IG: Post-test individual scores.

\begin{tabular}{|c|c|c|}
\hline \multicolumn{3}{|c|}{$\begin{array}{c}\text { IG } \\
\text { Post-test scores }\end{array}$} \\
\hline Learners & Unrelated Set & Related Set \\
\hline 1 & 4 & 5 \\
\hline 2 & 8 & 6 \\
\hline 3 & 10 & 8 \\
\hline 4 & 10 & 8 \\
\hline 5 & 3 & 4 \\
\hline 6 & 10 & 2 \\
\hline 7 & 10 & 10 \\
\hline 8 & 5 & 7 \\
\hline 9 & 7 & 10 \\
\hline 10 & 10 & 3 \\
\hline 11 & 8 & 9 \\
\hline 12 & 10 & 4 \\
\hline 13 & 10 & 10 \\
\hline 14 & 10 & 10 \\
\hline 15 & 10 & 9 \\
\hline 16 & 10 & 10 \\
\hline 17 & 8 & 10 \\
\hline 18 & 10 & 5 \\
\hline 19 & 10 & 8 \\
\hline 20 & 10 & 10 \\
\hline 21 & 10 & 7 \\
\hline 22 & 10 & 6 \\
\hline 23 & 10 & 8 \\
\hline 24 & 10 & 8 \\
\hline Mean Score & 8,87 & 7,37 \\
\hline
\end{tabular}


Table 4: BG: Post-test individual scores

\begin{tabular}{|c|c|c|}
\hline \multicolumn{3}{|c|}{$\begin{array}{c}\text { BG } \\
\text { Post-test scores }\end{array}$} \\
\hline Learners & Unrelated Set & Related Set \\
\hline 1 & 9 & 1 \\
\hline 2 & 1 & 3 \\
\hline 3 & 10 & 4 \\
\hline 4 & 7 & 5 \\
\hline 5 & 5 & 1 \\
\hline 6 & 5 & 2 \\
\hline 7 & 10 & 7 \\
\hline 8 & 6 & 8 \\
\hline 9 & 6 & 5 \\
\hline 10 & 10 & 4 \\
\hline 11 & 3 & 1 \\
\hline 12 & 1 & 2 \\
\hline 13 & 10 & 2 \\
\hline 14 & 7 & 0 \\
\hline 15 & 7 & 6 \\
\hline 16 & 1 & 2 \\
\hline 17 & 8 & 7 \\
\hline 18 & 1 & 10 \\
\hline 19 & 6 & 8 \\
\hline 20 & 7 & 8 \\
\hline 21 & 2 & 5 \\
\hline 22 & 8 & 3 \\
\hline 23 & 4 & 8 \\
\hline 24 & 10 & 5 \\
\hline 25 & 6 & 10 \\
\hline 26 & 10 & 2 \\
\hline 27 & 10 & 10 \\
\hline 28 & 7 & 10 \\
\hline 29 & 0 & 6 \\
\hline 30 & 10 & 7 \\
\hline 31 & 7 & 8 \\
\hline 32 & 10 & 10 \\
\hline 33 & 10 & 0 \\
\hline Mean Score & 6,48 & 5,15 \\
\hline
\end{tabular}


As can be seen in Tables 3 and 4, individual results are more homogeneous in the IG. In this group most learners obtained better scores in the unrelated set. To be more precise, only six learners did better with the related set and the superiority of these six learners over the unrelated set only ranges from one to three words. In the BG, on the other hand, the number of learners who obtained better scores with the unrelated set is 18 , that is, only slightly higher than the number of learners who did better with the related set, namely, 13 .

In addition, in the BG the differences between the scores obtained with both techniques are higher than in the IG (mean difference in the BG: 3,75; mean difference in the IG: 2,3) and less homogeneous across individuals. Thus, most differences in the IG rank between one or three words and when the difference is bigger, it always favours the unrelated set (see learners $6,10,12,18,22$ ). By contrast, in the BG the differences are higher with 14 learners displaying differences that range from four to ten words.

Finally, in the IG 17 learners answered the ten words correctly with the unrelated set while only seven did so with the related set, and from these seven, five correspond to learners who also answered the ten words correctly in the unrelated set, that is, learners who seem to be very good have been equally successful with both treatments. In stark contrast, in the BG ten learners answered all the words correctly with the unrelated set and only five with the related set. In addition, only two learners (learners 27 and 32) obtained the full score with both sets whereas the rest obtained very different scores in both tests, learner 33 being the most extreme without a single correct word in the related set.

In conclusion, while the tendency favours the unrelated set in both groups, the results in the BG seem to be less consistent, these learners often obtain very different scores in both tests and it is really hard to find a homogeneous pattern while the IG shows greater consistency and homogeneity.

The results presented in this section clearly favour the presentation of vocabulary in semantically unrelated sets over the presentation in semantically related sets. This finding answers our research question: these two ways of presenting vocabulary are not equally effective; students retain more vocabulary when working with words in semantically unrelated sets, at least in the short term. Also, our results go along with the empirical studies presented above (Erten and Tekin, 2008; Finkbeiner and Nicol, 2003; Schneider, Healy, and Bourne, 1998; Tinkham, 1993, 1997; Waring, 1997) and make the objections to semantically related sets stronger.

Likewise, our results concur with the results presented by Papathanasiou (2008), who also found that the learners did better with unrelated sets of words. This author also found that adults performed better than children despite having a lower command of English. In our case, the learners in both groups are adults (15 and 18 years old) and the group with the higher level is the group that has obtained better scores. Therefore, we confirm, complete and extend the effectiveness of presenting new vocabulary in unrelated sets to Spanish speaking secondary school students and we also claim that, among adults, it seems that the higher the level the more homogeneous this trend seems to be.

Obviously, the present study has some limitations that need to be taken into account and therefore we should be very cautious when interpreting our findings. First of all, we would need a delayed post-test to analyse retention of the words in the long term. Also, different types of tests could be considered, as we only measured the recognition of new vocabulary in the written form. As for the word sets, it might also be the case that one set is 
intrinsically easier for the students than the other. All in all our results are very preliminary, however, we believe that they could be taken as indicators of a possible trend that should be further explored in the future with larger populations, along a longer period of time and with different and larger sets of words and different types of post-tests.

\section{Final conclusions}

This study was originally motivated by an interest in pedagogical approaches towards the presentation of new vocabulary to EFL learners in secondary school. As the opening sentence of this article reads, on many occasions, teachers base their practices on popular beliefs about language learning or they simply take the validity of previous practices for granted and teach as they were taught. This seems to be the case with the presentation of vocabulary in semantically related word sets. Therefore, we wanted to test the effectiveness of presenting vocabulary in semantically related sets by comparing it to presenting vocabulary in unrelated sets with two intact classes of Spanish EFL learners in school and also to compare our results to those of a similar study in the Greek context (Papanathasiou 2008).

Our results favour the presentation of vocabulary in unrelated sets, especially with higher level students, and agree with the findings of Papathanasiou (2008) in the Greek context and with the findings of many empirical studies carried out in different settings (Erten and Tekin, 2008; Finkbeiner and Nicol, 2003; Schneider, Healy, and Bourne, 1998; Tinkham, 1993, 1997; Waring, 1997). Thus, our results also suggest the re-evaluation of the common pedagogical practice of always presenting words in semantically related sets. However, unlike some authors (Tinkham 1993, 1997; Waring1997), we do not believe that the presentation of semantically related vocabulary together impedes rather than facilitate learning and therefore should be discouraged. On the contrary, in our case, both groups have obtained scores beyond 50 per cent with both treatments, and therefore both techniques seem to be effective although one is more effective than the other. The fact that the learners had to use a great variety of learning strategies when the new words were presented with both techniques has probably contributed to these positive results. Also, we are aware that teaching vocabulary in semantically related sets follows the communicative needs of EFL learners, is reflected in the structure of textbooks and, consequently, it is simply much easier for teachers to teach words that are semantically related at the same time. Therefore, in our view, there is no reason to discourage the presentation of semantically related words and what we recommend is that teachers combine both techniques, that is, that when presenting semantically related fields they could also introduce unrelated terms in their language classes.

To finish, we would like to highlight the value of the present study for pedagogical practice because, in the same way as Papathanasiou's (2008), it was carried out in a natural EFL setting, a Spanish secondary school, and natural teaching procedures were used. Thus, we believe that our study could be applied to other natural EFL learning situations in which teachers could make use of our findings to help their students more effectively with the acquisition of vocabulary. We are aware of the difficulty of changing some pedagogical practices and of teaching vocabulary in an unrelated way, however, we think it would be very positive if teachers, and textbook writers, would start exploring the possibility of adding unrelated words to the semantically related sets when preparing their lessons. 


\section{REFERENCES}

Aitchison, J. (1994) (2 ${ }^{\text {nd }}$ edition). Words in the Mind: An Introduction to the Mental Lexicon. Blackwell Publishers, Great Britain.

Aitchison, J. (1996). "Taming the wilderness: words in the mental lexicon", in G.M. Anderman and M.A. Rogers (eds.), Words, Words, Words: The Translator and the Language Learner. Great Britain: Multilingual Matters: 15-26.

Allen, J. (1999). Words, Words, Words. Maine: Stenhouse Publishers.

Anderson, M.C. (2003). "Rethinking interference theory: executive control and the mechanisms of forgetting", in Journal of Memory and Language, 49: 415-445.

Bogaards, P. and Laufer, B. (eds.) (2004). Vocabulary in a Second Language: Selection, Acquisition and Testing. Benjamins, Amsterdam.

Çalişkana, M. \& Sünbül, A. M. (2011). "The effects of learning strategies instruction on metacognitive knowledge, using metacognitive skills and academic achievement (Primary Education Sixth Grade Turkish Course Sample)", in Educational Sciences: Theory \& Practice, 11, 1: 148-153.

Channell, J. (1981). "Applying semantic theory to vocabulary teaching", in ELT Journal, 37, 2 : 115-22.

Coady, J. and Huckin, T. (eds.) (1997). Second Language Vocabulary Acquisition: a Rationale for Pedagogy. Cambridge University Press, Cambridge.

Council of Europe (2001). Common European Framework of Reference for Languages: Learning, Teaching, Assessment. Cambridge: Cambridge University Press.

Erten, I.H. and Tekin, M. (2008). "Effects of vocabulary acquisition of presenting new words in semantic sets versus semantically unrelated sets", in System, 36, 3: 407-422.

Finkbeiner, N. and Nicoll, J. (2003). "Semantic category effects in second language word leaning", in Applied Psycholinguistics, 24: 369-383.

Folse, K.S. (2004). Vocabulary Myths: Applying Second Language Research to Classroom Teaching. University of Michigan Press, Michigan.

Grandy, R.E. (1992). "Semantic fields, prototypes, and the lexicon", in A. Lehrer and E.F. Kittay (eds.), Frames, Fields, and Contrasts: New Essays in Semantic and Lexical Organization. New York: Lawrence Erlbaum Associates: 105-120.

Hashemi, R.H. and Gowdasiaei, F. (2005). "An attribute-treatment interaction study: lexical-set versus semanticallyunrelated vocabulary instruction", in Regional Language Centre Journal 36, 3: 341-361.

Haycraft, J. (1993). An Introduction to English Language Teaching. Malaysia: Longman.

Jullian, P. (2000). "Creating word meaning awareness", in ELT Journal, 54, 1: 37-46.

Khalil, A. (2005). "Assessment of language learning strategies used by Palestinian EFL learners", in Foreign Language Annals, 38, 1: 108-119.

Nemati, A. (2009). "Memory vocabulary learning strategies and long-term Retention", in International Journal of Vocational and Technical Education, Vol. 1(2), pp. 14-24.

Papathanasiou, E. (2008). "An investigation of two ways of presenting vocabulary", in ELT Journal 63, 4: 313-22.

Read, J. (2000). Assessing Vocabulary. Cambridge: Cambridge University Press.

Richards, J.C. and Renandya, W.A. (2002). Methodology in Language Teaching: An Anthology of Current Practice. Cambridge: Cambridge University Press.

Schneider, V.I.; Healy, A.F. and Bourne, L.E. (1998). "Contextual interference in foreign language vocabulary acquisition and retention”, in A.F. Healy and L.E. Bourne (eds.), Foreign 
Language Learning: Psycholinguistic Studies on Training and Retention. Mahwah, NJ: Lawrence Erlbaum.

Seal, B.D. (1991). "Vocabulary learning and teaching", in M. Celce-Murcia (ed.), Teaching English as a Second or Foreign Language. USA: Heinle and Heinle Publishers: 296-311.

Shapiro, A. M., \& Waters, D. L. (2005). “An investigation of the cognitive processes underlying the keyword method of foreign vocabulary learning", in Language Teaching Research, 9, 2: 129-146.

Stoller, F.L. and Grabe, W. (1995). "Implications for L2 vocabulary acquisition and instruction from L1 vocabulary research", in T. Huckin, M. Haynes and J. Coady (eds.), Second Language Reading and Vocabulary Learning. Norwood, Norwood, NJ: Ablex Publishing Corporation: 24-45.

Tinkham, T.N. (1993). "The effects of semantic and thematic clustering on the learning of second language vocabulary", in System, 21, 3: 371-80.

Tinkham, T.N. (1997). "The effects of semantic and thematic clustering on the learning of second language vocabulary", in Second Language Research, 13, 2: 261-74.

Tseng, W.-T, Dornyei, Z., \& Schmitt, D. (2006). "A new approach to assessing strategic learning: The case of self-regulation in vocabulary acquisition", in Applied Linguistics, 27, 1: 78-102.

Waring, R. (1997). "The negative effects of learning words in semantic sets: A replication", in System, 25, 2: 261-274.

Wharton, S. and Race, P. (1999). 500 Tips for TESOL. Kogan Page, Great Britain.

Willis, D. and Willis, J. (2007). Doing task-based teaching. A practical guide to task-based teaching for ELT training courses and practising teachers. Oxford: Oxford University Press.

Xhaferi, B. \& Xhaferi, G. (2008). Vocabulary learning strategies used by students at SEEU in terms of gender and teachers' attitudes toward teaching vocabulary. Tetovë: SEEU.

Zhi-liang1's, L. (2010). "A Study on English Vocabulary Learning Strategies for Non-English Majors in Independent College", in Cross-Cultural Communication, 6, 4: 152-164. 


\section{APPENDIX A}

\section{Lesson Plan: Unrelated vocabulary}

Set of words: currency, lawnmower, butler, beak, coal, tailor, grab, sleeve, bush, steamed

Procedure for vocabulary presentation:

a. Picture

b. Pronunciation - Students repeat.

c. Students try to guess the written form of the word.

d. English definition.

e. Spanish translation.

f. Examples: Sentences with the words in them.

The currency used in Spain is Euro.

We need to get our lawnmower repaired before next Friday.

The butler was a tall and dark man who did not seem to be very happy to have need guests in the house.

Woodpeckers, a type of bird, hit their beaks against a tree trunk to make a hole in it big enough for two birds to sit in.

As black as coal

A tailor made Paul a new suit.

The thief grabbed my bag and ran away before I could even see his face.

I loved the shirt but the sleeves were a bit too short so I did not buy it.

The cat was hiding behind one of the bushes in the garden.

Strangely, steamed food has not been widely embraced by Western chefs other than for special dishes and puddings

g. Eliciting vocabulary. Students talk in pairs, then we share with the rest of the group. What currency do they use in the United Kingdom?

Have you ever used a lawnmower? Is it possible to repair the lawnmower?

Do you think there are still houses where they keep a butler?

What do birds use their beaks for? What colour is the birds' beak?

Do you know people who use coal to keep their houses warm in winter?

Do you prefer going to a tailor to have a new dress/suit made or buying one in a shop?

Have a thief ever grabbed your bag, purse, etc.?

What would you do if one of the sleeves of your favourite shirt gets torn?

If you got lost in a forest, would you eat from an unknown berry bush?

Do you think steamed food is healthy?

h. Consolidation activity: Fill in the gaps.

In economics, refers to physical objects generally accepted as a means

to pay for goods.

The new was a tall and very serious man with a foreign accent. 
The strange man suddenly his jacket and ran away.

When I went to see the he was still repairing the of my new suit.

We found a small bird with a big hiding in a

My dad bought a new ... last Friday.

They spent a wonderful week on the coast, sunbathing and eating blue crabs at the local crab houses.

In Spain, children receive a piece of at Christmas if they have not been good throughout the year.

\section{Lesson Plan: Related vocabulary}

Set of words: ditch, sewer, tramp, cul-de-sac, launderette, railing, kerb, passer-by, downtown, outskirts.

Procedure for vocabulary presentation:

a. Picture

b. Pronunciation - Students repeat.

c. Students try to guess the written form of the word.

d. English definition.

e. Spanish translation.

f. Examples: Sentences with the words in them.

I was driving too fast and my car went out of control and plunged into a ditch.

The Romans had complex sewer systems, similar to the ones we have nowadays.

Every day I meet a tramp sitting outside a bank.

One of the reasons we live on a cul-de-sac is because safety for kids is relatively higher there.

When I lived in a student dorm, I used to take my clothes to the launderette every Friday.

If you build a high deck, you will probably need to install a railing.

As I was talking to my mum, I fell off the kerb and sprained my ankle.

Many passers-by witnessed the incident.

Most bars and restaurants are in the downtown area.

They are building a new swimming pool on the outskirts of the city.

g. Eliciting vocabulary. Students talk in pairs, then we share with the rest of the group. Why do you think the maintenance of road ditches is important?

Is it possible to make a living from combing for treasures the sewers of a big city? Why do you think tramps live like that? How can we help them?

Are deck railings necessary for safety? Are they there only for style?

Would you prefer to live downtown or on the outskirts of a city?

Have you ever used a launderette? When? Why?

Have you (or someone you know) ever hurt yourself from falling off a kerb? 
Do you mind asking passers-by for directions when you are in a different city?

What do you think the benefits of living in a cul-de-sac neighborhood are?

h. Consolidation activity: Fill in the gaps.

Each time you flush the toilet or wash something, you create wastewater, which goes to the

The car hit the

Every Saturday my friends and I go and stay there for the evening.

A ……............... saw the accident and called the police.

People who do not have their own washing machine have to go to a

They moved to the of London.

Do not lean bicycles on the

We had less traffic living on the

A …............... is a long-term homeless person who travels from place to place.

Road need cleaning from time to time.

\section{APPENDIX B}

\section{Sample test sheet: Related vocabulary}

1. Please, match the following words to their definitions:

1. Ditch

a) A short road which is blocked off at one end.

2. Sewer

b) Central or main area of a city.

3. Tramp

c) The outer area of a city, town or village.

4. Cul-de-sac

d) A long, narrow hole in the ground next to a road.

5. Launderette

e) The line of stones at the edge of a pavement.

6. Outskirts

f) An underground system for carrying off drainage water and waste matter.

7. Railings

g) Someone who is walking past something or someone.

8. Passer-by

h) Someone who has no home, job, or money and who lives outside.

9. Downtown

i) A shop where you pay to use the machines there which will wash and

10. Kerb dry clothes.

\section{Can you give the Spanish translation of these words?}

Sample test sheet: Unrelated vocabulary

\section{Please, match following the words to their definitions:}

1. Beak

a) The money that is used in a particular country at a particular time.

2. Bush

b) The hard pointed part of a bird's mouth.

3. Tailor

c) A hard, black substance which is dug from the earth in pieces, and can be burnt to produce heat or power. 
4. Sleeve d) To take hold of something or someone suddenly and roughly.

5. Grab e) The most important male servant in a house, usually responsible for organizing the other servants.

6. Currency f) A machine used for cutting grass.

7. Lawnmower g) A plant with many small branches growing either directly from the ground or from a hard woody stem, giving the plant a rounded shape.

8. Steamed h) The part of a piece of clothing that covers some or all of the arm.

9. Butler i) Someone whose job is to repair, make and make changes to clothes...

10. Coal j) Cooked over a saucepan of boiling water.

\section{Can you give the Spanish translation of these words?}

